\title{
Anti-helmintic Activity of Myrtus communis L. Fruit Ethanol Extract on Nematodes of Caenorhabditis elegans and The Determination of Possible Active Ingredients
}

Hulya Ozpinar ${ }^{(D)}$

Sivas Cumhuriyet University, Department of Pharmaceutical Botany, Sivas, Turkey

\section{ABSTRACT}

yrtus communis L. (Myrtaceae) is a plant widely found in the Middle East and Medi1 terranean region, both naturally grown and cultivated. In our study, C. elegans nematodes were used as an anti-helminthic model and by determining the anti-helmintic effect of Myrtus communis L. fruit, it was aimed to find the active ingredients with possible antihelmintic effects by GC-MS analysis. In our study, the anthelmintic effect of the ethanol extract of Myrtus communis L. fruit on C. elegans was investigated. Ethanol fruit extracts were added to NGM separately at final volume of $10 \mathrm{mg} / \mathrm{mL}, 5 \mathrm{mg} / \mathrm{mL}, 2.5 \mathrm{mg} / \mathrm{mL}, 1.25$ $\mathrm{mg} / \mathrm{mL}$ and experimental groups were formed. When the data were evaluated statistically, the difference between all experimental groups, negative control group and positive control group (pyrantel pamoate), was significant $(\mathrm{p}<0.05)$. According to the results of GCMS analysis, the highest detected ingredients were 1,8-Cineole (3.46\%), Linalyl acetate (3.06\%), and Palmitic acid (2.90\%). It was observed that Myrtus communis L. fruit extract was more effective on $C$. elegans nematodes than pyrantel pamoate at the same concentration $(5 \mathrm{mg} / \mathrm{mL})$, and 20 different active ingredients were determined according to our GCMS analysis results. By studying the forms of these active ingredients separately or in different combinations, the ingredients and combinations with the strongest anti-helmintic activity can be determined, and it is thought that our findings may lead to further studies.
Article History:

Received: 2021/08/17 Accepted: 2021/08/26 Online: 2021/og/29

Correspondence to: Hulya Ozpinar, Sivas Cumhuriyet University, Faculty of Pharmacy, Department of Pharmaceutical Botany, 58140 Sivas/Turkey

E-Mail:hulya1177@yahoo.com.tr

Keywords:

Myrtus communis L.; Caenorhabditis elegans; anti-helmintic effect; 1,8-Cineole; Linalyl acetate; Palmitic acid

\section{INTRODUCTION}

$M$ yrtus communis L. (Myrtaceae) is one of the characteristic representatives of the Mediterranean flora. This species widely found in the Middle East and Mediterranean Region is both naturally grown and cultivated [1]. Myrtus communis L. is an evergreen shrub that can grow to 1-5 meters approximately. The oppositely arranged leaves are ovate-lanceolate, 2-5 cm long, coriaceous, glabrous, punctuateglandular, and entire. The flowering period lasts from June to September. Subglobose to ellipsoid fruits are blue-black (or rarely yellowish-white) when ripe [2]. Different parts of this plant such as fruits, branches, leaves, and seeds have been extensively used in traditional medicine. Traditionally used as an antiseptic, disinfectant, and hypoglycemic agent, its leaves and fruits have been used as an antiseptic drug in villages of Turkey [3]. Similarly, in Italian traditional medicine, the fruit of this plant is used in the treatment of many types of infectious diseases, including diarrhea and dysentery [4]. The leaves are used as an antiseptic and anti-inflammatory agent and as a mouthwash in the treatment of candidiasis $[4,5]$. In addition, antibacterial [6], antifungal [7], and antioxidant [8] effects are frequently mentioned in the literature.

Helminthiasis is one of the important parasitic diseases, many of which are zoonotic, especially in developing countries and especially in countries with hot and humid climates. Although not as much as in tropical countries, helminthiasis is quite common in some settlements of Turkey due to insufficient infrastructure and lack of education. Intestinal parasitosis can cause significant manifestations at all levels of the gastrointestinal tract, as well as anemia and growth retardation. Cholecystitis, cholangitis, liver abscess, pancreatitis, ileus, and acute appendicitis are significant complications [9]. In addition, helminth infections are one of the most important causes of growth deficiency and intellectual 
development retardation in developmental ages [10]. Parasitic diseases cause many problems, especially in children of developmental age, such as malnutrition, developmental retardation, anemia, attention deficit, learning difficulties and consequently decreased success levels. Such health problems observed in primary and secondary education children cause children to lag behind in both physical and psychological development compared to their peers. Studies have mentioned the effects of helminth infections on the school performance of infected children and the future of the country [11]. In addition, it has been reported that these infections may have a detrimental effect on cognition and educational success in terms of intellectual development [11-13]. As a result, people's turn to anthelmintic drugs has also been one of the reasons for the development of resistance $[14,15]$. As with many disease agents, the development of resistance to the drug of parasites causes parasitic diseases to be a public health problem and difficulties in their treatment $[14,15]$. In recent years, the use of herbal medicines has been increasing exponentially. Many plants are used as a means of treatment for various diseases, and the effects that can replace synthetic drugs are seen. Products obtained from plants have been used since ancient times as a traditional treatment method, especially in the eradication of pathogens that develop drug resistance [16].

Studies on the anthelmintic activities of medicinal plants are very few. One of the reasons is that most of the helminths cannot be cultured in the laboratory environment. Therefore, laboratory animals such as rats or mice are generally preferred as models in such studies. However, animal studies bring many problems such as requiring a lot of labor, shortage of workspace, and being expensive [16]. $\mathrm{Ca}$ enorhabditis elegans (C. elegans), Class: Chromadorea, Order: Rhabditida, Family: Rhabditidae, Genus: Caenorhabditis, Species: Caenorhabditis elegans is a nematode also called threadworm. C. elegans can be a good anti-helmintic model, studies have reported [16-18].

In our study, $C$. elegans nematodes were used as an anti-helminthic model and the anti-helminthic effect of Myrtus communis L. fruit was determined, and it was aimed to determine the active ingredients with possible antihelmintic effects by GC-MS analysis.

\section{MATERIAL AND METHODS}

\section{Plant Material}

The Myrtus communis L. fruit used in our study was purchased in equal amounts from 10 different vendors sold commercially in Hatay province.

\section{Preparation of Plant Extracts}

Myrtus communis L. fruit plant extracts were used in our study. The samples were first washed with tap water and then pure water, then dried on drying paper. Fruits that purchased from different vendors were grounded in equal proportions and homogenized. $100 \mathrm{~g}$ was taken from the powdered plant materials. Added $300 \mathrm{~mL}$ ethanol on top. It was kept at room temperature in the shaker at 150 $\mathrm{rpm}$ for $24 \mathrm{~h}$. At the end of that time, it was filtered twice by the No:1whatman filter payper. Ethanol in the resulting liquid part was completely evaporated in the evaporator (Buchi R-100 equipped with Vacuum Pump V-300 and Control unit I-300).

\section{GC-MS Analysis}

For GC-MS, the HP-5 MS IU capillar column (30 m X $250 \mu \mathrm{m} \mathrm{X} 0.25 \mu \mathrm{m})$ and the 7890A (Agilent) model GCMS device with 5975C (Agilent) inert MSD mass detector were used. In GC-MS, an electron ionization system with $70 \mathrm{eV}$ ionization energy and He was used as carrier gas with $99.999 \%$ purity. The carrier gas entered the He column with a flow rate of $1.5 \mathrm{~mL} / \mathrm{min}$ and a starting pressure of 17,897 psi. After keeping the oven temperature at the starting temperature of $50^{\circ} \mathrm{C}$ for 2 minutes, the rate of temperature rise in all stages was $5^{\circ} \mathrm{C} / \mathrm{min}$ and was increased to $80^{\circ} \mathrm{C}$ (waiting 2 minutes at this temperature), $100^{\circ} \mathrm{C}$ (waiting 1 minute at this temperature), $150^{\circ} \mathrm{C}$ (waiting 1 minute at this temperature), $240^{\circ} \mathrm{C}$ (waiting 1 minute at this temperature) and $270^{\circ} \mathrm{C}$ (waiting $7 \mathrm{minu}$ tes at this temperature), respectively.

The GC-MS analysis was performed by the Giresun University Central Research Laboratory Application and Research Centre, Giresun, Turkey.

\section{Anti-helmintic Activity}

\section{Obtaining C. elegans Strains}

The strain of wild type C. elegans N2 was purchased from the Ceanorhabditis Genetic Center (University of Minnesota, Minneapolis, USA).

\section{Synchronization of C. elegans nematodes}

About 20 adults C. elegans were transferred to the Nematot Growth Media (NGM) petri dish containing E. coli OP50. After laying for 4-6 hours, adults C. elegans were removed from the petri dish. These eggs formed synchronized offspring. These were used in the study when it came to adult form at the end of the 3rd day. 
This procedure was carried out with 5 petri at the same time to provide sufficient nematodes for the study.

\section{Preparation of Nematode Growth Media}

A $2.5 \mathrm{~g}$ peptone, $3 \mathrm{~g} \mathrm{NaCl}$, and $20 \mathrm{~g}$ agar were dissolved in $1 \mathrm{~L}$ of distilled water. After autoclaving at $125^{\circ} \mathrm{C}$ for 15 min, the mixture was cooled to $55^{\circ} \mathrm{C}$. Homogenization was obtained by adding $1 \mathrm{~mL} \mathrm{MgSO} 4(1 \mathrm{M}), 1 \mathrm{~mL}$ cholesterol ( $5 \mathrm{mg} / \mathrm{mL}), 1 \mathrm{~mL} \mathrm{CaCl} 2$ (1M), $25 \mathrm{~mL}$ KH2PO4 buffer ( $\mathrm{pH}$ 6), which had been previously prepared and filtered through a $0.2 \mu \mathrm{m}$ mesh, to the medium. Myrtus communis L fruit extracts were added to NGM separately, with final concentrations of $10 \mathrm{mg} / \mathrm{mL}, 5 \mathrm{mg} / \mathrm{mL}, 2,5 \mathrm{mg} /$ $\mathrm{mL}, 1,25 \mathrm{mg} / \mathrm{mL}$ and experiment groups were formed. In addition, $10 \mathrm{~mL}$ was taken from Kontil $(250 \mathrm{mg} / 5 \mathrm{~mL})$, which is used as an antihelmintic drug and whose active ingredient is pyrantel pamoate and dissolved within $100 \mathrm{~mL}$ NGM and prepared in a concentration of $5 \mathrm{mg} /$ $\mathrm{mL}$. It formed this positive control group. The negative control group was created only from NGM. NGM was transferred $10 \mathrm{~mL}$ each to petri dish and, the prepared $E$. coli OP50 strain was added to NGM.

\section{Determination of Anti-helmintic Activity}

In order to determine the anti-helmintic effect of plant extracts on C. elegans, 20 synchronized adult C. elegans were transferred to NGMs containing plant extracts and E. coli OP50. The number of live and dead nematodes was recorded under a stereo microscope every day for 21 days. Each concentration was studied with 5 petri dishes, and the work was repeated 2 times. Nematodes who had completely lost their pharynx pumping movements were considered dead.

\section{Statistical analysis}

The data obtained in our study were evaluated in the SPSS (Ver: 22.0) program and the One- Way Anova and Tukey test was used, the level of error was taken as 0.05 .

\section{RESULTS}

According to our study results, no adult nematodes were found in the sample of Myrtus communis L. fruit extract on the 6th day at all concentrations included in the study It was found that there are no living nematodes at the end of the second day at the first concentration of the study, $10 \mathrm{mg} / \mathrm{mL}$, at the end of the third day at the concentration of $5 \mathrm{mg} / \mathrm{mL}$, at the end of the fifth day at the concentration of $2.5 \mathrm{mg} / \mathrm{mL}$, and at the end of the 6 th day at the concentration of $1.25 \mathrm{mg} / \mathrm{mL}$. According to the data of pyrantel pamoate $(5 \mathrm{mg} / \mathrm{mL})$ used as a positive control were examined, the presence of live nematodes was observed until the 10th day. In the negative control group, which was not exposed to any active substance, live nematodes were observed until the 21st day (Fig. 1, Fig. 3, Fig. 4, Table 2). When the data were evaluated statistically, the difference between all experimental groups, negative control group and positive control group (pyrantel pamoate), was significant $(\mathrm{p}<0.05)$. According to our findings, Myrtus communis L. fruit extract was found to be more effective on C. elegans nematodes than pyrantel pamoate at the same concentration $(5 \mathrm{mg} / \mathrm{mL})$.

The main components determined as a result of GCMS analysis are shown in Table 1, Figure 2. According to the analysis, the highest detected ingredients were 1,8-Cineole (3.46\%), Linalyl acetate (3.06\%), and Palmitic acid (2.90\%).

\section{DISCUSSION}

In our study, the anti-helmintic activity of Myrtus communis L. fruit extract on C. elegans nematodes was investigated. Many medicinal effects of Myrtus communis L. have been mentioned in the literature [3-7]. In addition, there are studies showing the antiparasitic effect of Myrtus communis L. In a study, potent prophylactic effects of essential oils of Myrtus communis L. were shown in mice infected with Toxoplasma gondii, especially at doses of 200 and $300 \mathrm{mg} / \mathrm{kg}$ [19]. Another study was carried out on promastigote and amastigote forms of Leishmania tropica and it was shown that the essential oils of Myrtus communis L. significantly inhibited their growth

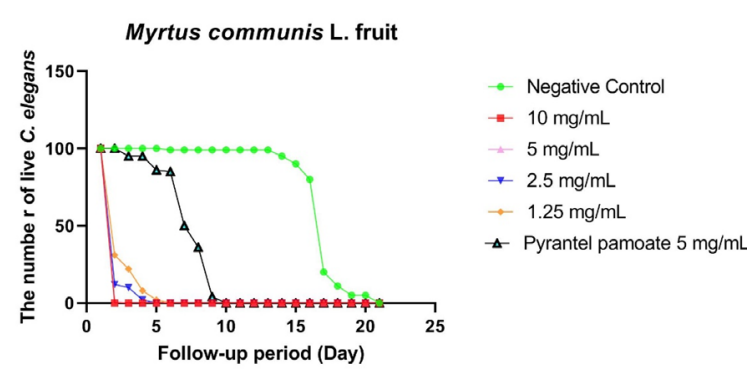

Figure 1. Anti-helminthic activity of Myrtus communis L. fruit extract on C. elegans nematodes

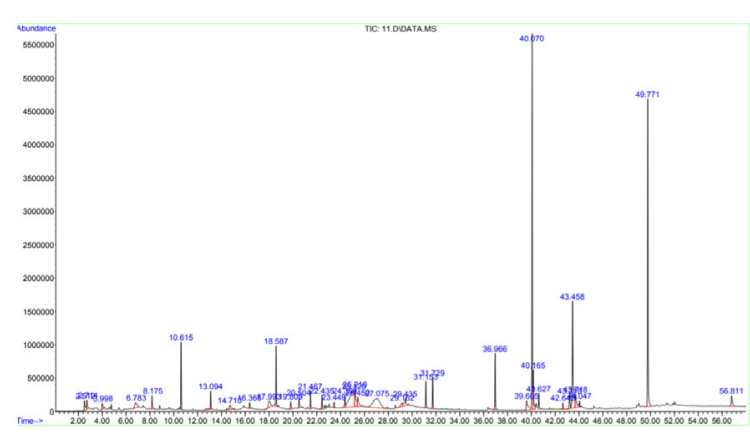

Figure 2. GC-MS chromatogram of Myrtus communis L. fruit ethanol extract 


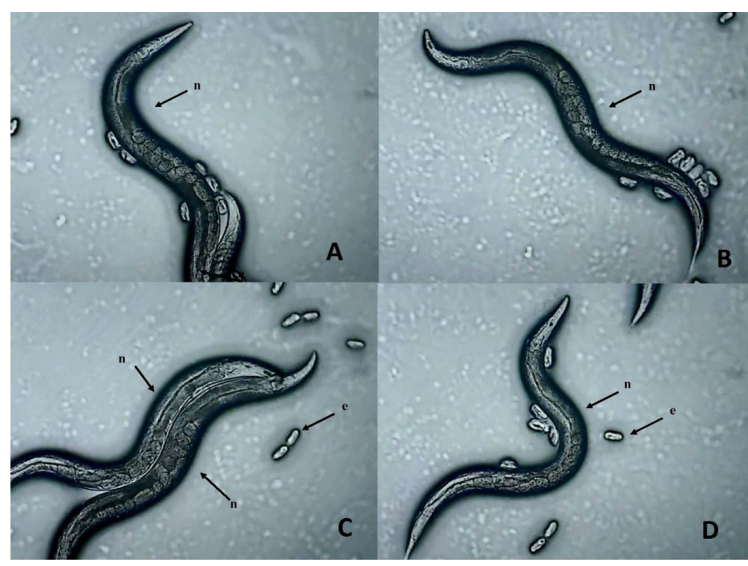

Figure 3. C. elegans live nematodes (n: C. elegans L4 form, e: egg)

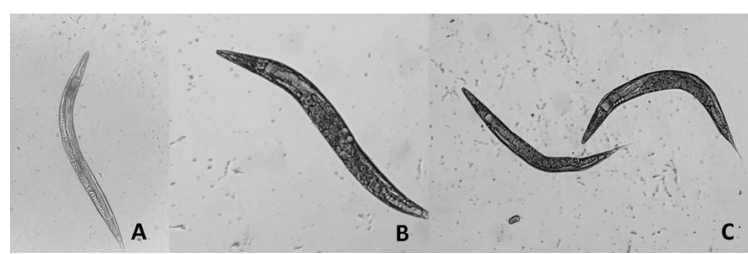

Figure 4. $A, B, C$ Dead nematodes

Table 1. GC-MS results of Myrtus communis L. fruit extract

\begin{tabular}{|c|c|c|}
\hline Bileșen Adı & RT & Ethanol(\%) \\
\hline Acetic acid & 2.513 & 0.81 \\
\hline 9-Octadecenamide & 2.513 & 0.81 \\
\hline 2-Propenoic acid & 3.995 & 0.45 \\
\hline 2-Heptenal & 8.178 & 0.82 \\
\hline 1,8-Cineole (Eucalyptol) & 10.616 & 3.46 \\
\hline Linalool & 13.093 & 1.37 \\
\hline 4H-Pyran-4-one & 14.713 & 0.78 \\
\hline$\beta$-Fenchyl Alcohol & 16.366 & 0.38 \\
\hline 5-Hydroxymethylfurfural & 17.991 & 1.29 \\
\hline Linalyl acetate & 18.586 & 3.06 \\
\hline 2,4-Decadienal & 20.503 & 0.72 \\
\hline Camphene & 21.465 & 0.90 \\
\hline (+)-4-Carene & 21.465 & 0.90 \\
\hline Geranyl acetate & 22.437 & 0.69 \\
\hline trans-Caryophyllene & 23.450 & 0.32 \\
\hline beta-Selinene & 24.360 & 0.77 \\
\hline Palmitic acid & 36.965 & 2.90 \\
\hline 9,12-Octadecadienoic acid & 39.603 & 1.58 \\
\hline Stearic acid & 40.627 & 0.98 \\
\hline D-alpha-Tocopherol & 56.809 & 1.25 \\
\hline
\end{tabular}

in a dose-dependent manner. In a study, The IC50 values of essential oil and methanolic extract were reported as 8.4 and $28.9 \mu \mathrm{g} / \mathrm{mL}$ against promastigotes, and 11.6
Table 2. Number of live C. elegans exposed to different doses of Myrtus communis L. fruit ethanol extract

\begin{tabular}{|c|c|c|c|c|c|c|}
\hline Days & Control & $\begin{array}{l}\text { Pyrantel } \\
\text { pamoate } \\
5 \mathrm{mg} / \mathrm{mL}\end{array}$ & $\begin{array}{c}10 \\
\mathrm{mg} / \\
\mathrm{mL}\end{array}$ & $\begin{array}{c}5 \\
\mathrm{mg} / \\
\mathrm{mL}\end{array}$ & $\begin{array}{c}2.5 \\
\mathrm{mg} / \\
\mathrm{mL}\end{array}$ & $\begin{array}{c}1.25 \\
\mathrm{mg} / \\
\mathrm{mL}\end{array}$ \\
\hline 1 & 100 & 100 & 100 & 100 & 100 & 100 \\
\hline 2 & 100 & 100 & 0 & 1 & 12 & 31 \\
\hline 3 & 100 & 95 & 0 & 0 & 10 & 22 \\
\hline 4 & 100 & 95 & 0 & 0 & 2 & 8 \\
\hline 5 & 100 & 86 & 0 & 0 & 0 & 2 \\
\hline 6 & 99 & 85 & 0 & 0 & 0 & 0 \\
\hline 7 & 99 & 50 & 0 & 0 & 0 & 0 \\
\hline 8 & 99 & 36 & 0 & 0 & 0 & 0 \\
\hline 9 & 99 & 4 & 0 & 0 & 0 & 0 \\
\hline 10 & 99 & 0 & 0 & 0 & 0 & 0 \\
\hline 11 & 99 & 0 & 0 & 0 & 0 & 0 \\
\hline 12 & 99 & 0 & 0 & 0 & 0 & 0 \\
\hline 13 & 99 & 0 & 0 & 0 & 0 & 0 \\
\hline 14 & 95 & 0 & 0 & 0 & 0 & 0 \\
\hline 15 & 90 & 0 & 0 & 0 & 0 & 0 \\
\hline 16 & 80 & 0 & 0 & 0 & 0 & 0 \\
\hline 17 & 20 & 0 & 0 & 0 & 0 & 0 \\
\hline 18 & 11 & 0 & 0 & 0 & 0 & 0 \\
\hline 19 & 5 & 0 & 0 & 0 & 0 & 0 \\
\hline 20 & 5 & 0 & 0 & 0 & 0 & 0 \\
\hline 21 & 0 & 0 & 0 & 0 & 0 & 0 \\
\hline
\end{tabular}

and $40.8 \mu \mathrm{g} / \mathrm{mL}$ against amastigote forms, respectively. In addition, it was emphasized in the study that Myrtus communis L. was not cytotoxic in the J774 cell line at the working concentrations [20]. In addition to these studies, the anti-parasitic effects of Myrtus communis L. on Giardia lamblia [21] and Trichomonas vaginalis [22,23] protozoa were also mentioned. In the literature review, there were not enough studies on the anti-helmintic activity of Myrtus communis L. fruits. In a study, water and ethanol extracts of the leaves of Myrtus communis L. investigated for the anti-helminthic activity on cattle strongyles nematodes, and this effect was evaluated by egg screening test and larval mortality test. It was determined that Myrtus communis L. leaf water and ethanol extracts have a potential anthelmintic activity on cattle strongyles parasite larvae [24].

As a result of GC-MS analysis, 1,8-Cineole (Eucalyptol), the oxygenated monoterpenes that we detected with the highest rate, were also detected at high rates in the essential oils of Artemisia lancea (34.56\%), Piper aduncum (55.8\%), 
and Rosmarinus officinalis (42.11\%). It was observed that essential oils of these species show high ovicidal and larvicidal activity on $H$. contortus [25-27].

Compounds such as beta-seline, palmitic acid, 9,12-Octadecadienoic acid, and camphene, which we determined as a result of GC-MS analysis of Myrtus communis L. fruit ethanol extract, were found in many plants have anthelmintic effects [28-34].

In a study by Taur et al. [35], the anti-helmintic activity of essential oil isolated from Eucalyptus globulus on the adult Indian worms Pheretima posthuma, which is anatomically and physiologically similar to human intestinal worm parasites, was investigated. As a result of this study, it was concluded that E. globulus oil has anthelmintic potential due to the presence of borneol, linalool, cineol, geranyl acetate, anethole, and saffron. The presence of these herbal components, linalool and geranyl acetate, in the fruit extract of Myrtus communis L., was determined as a result of our GC-MS analysis.

The active ingredients in herbal extracts sometimes act alone or sometimes in combination with several active ingredients. There are studies using some of these active ingredient combinations to prove anti-helmintic activity. For example, in a study with fatty acids such as palmitic acid and stearic acid as a result of GC-MS analysis, it was determined that some combinations of palmitic acid and stearic acid prevented the hatch rate of $H$. contortus species by $100 \%$. Likewise, as a result of GC-MS analysis, the highest rate of linalyl acetate (3.06\%), which we determined highest than the 1,8-Cineole (3.46\%) in the fruit extract of Myrtus communis L., was different combinations of $\alpha$-pinene, $\mathrm{p}$-cymene, thymol octanoate, and thymol acetate compounds were tested on pigs infected with Ascaris suum eggs, and the combination of $\alpha$-pinene, linalyl acetate, $\mathrm{p}$-cymene, and thymol octanoate was found to be quite effective [36].

In a study conducted by Matos-Rocha et al. [37], the schistosomicidal activity of sesquiterpenes such as alphahumulene and trans-caryophyllene in adult individuals of Schistosoma mansoni was evaluated in vitro and it was found that sesquiterpenes at non-lethal concentrations reduce the egg production and motor activity of the worms and cause death in some way depending on the concentration (100 and $200 \alpha / 4 \mathrm{~g} / \mathrm{mL}$ ). Trans-caryophyllene is one of the ingredient that we detected as a result of GC-MS analysis in our study.

\section{CONCLUSSIONS}

In our study, the anti-helmintic activity of Myrtus communis L. fruit extract on C. elegans nematodes was inves- tigated, and it was found that Myrtus communis L. fruit extract was more effective on C. elegans nematodes than pyrantel pamoate at the same concentration $(5 \mathrm{mg} / \mathrm{mL})$. According to our GC-MS results of Myrtus communis L. fruit extract, 20 different active ingredients were found. In the literature reviews, it has been shown in previous studies that some compounds such as 1,8-Cineole (Eucalyptol), linalool, geranyl acetate, linalyl acetate, and trans-caryophyllene have shown anti-helmintic activity. The presence of these active ingredients supports our experimental results. Via studying the forms of these active ingredients separately or in different combinations, the ingredients and combinations with the strongest antihelmintic activity can be found, and our findings may pave the way for further studies.

\section{CONFLICT OF INTEREST}

The author declares no financial, or otherwise, conflicts of interest.

\section{References}

1. Traveset A, Riera N, Mas RE. Ecology of fruit-colour polymorphism in Myrtus communis and differential effects of birds and mammals on seed germination and seedling growth. Journal of Ecology (2001) 749-760.

2. Morel J-P, Mercuri AM. Plants and Culture: seeds of the cultural heritage of Europe: Centro Europeo per. I Beni Culturali Ravello Edipuglia (2009) 1-284.

3. Baytop T. Therapy with medicinal plants in Turkey (Past and Present). Publication of the Istanbul University, Istanbul, 1999.

4. Aleksic V, Knezevic P. Antimicrobial and antioxidative activity of extracts and essential oils of Myrtus communis L. Microbiological Research 169 (2014) 240-254

5. Gortzi O, Lalas S, Chinou I, Tsaknis J. Reevaluation of bioactivity and antioxidant activity of Myrtus communis extract before and after encapsulation in liposomes. European Food Research And Technology 226 (2008) 583-590.

6. El Hartiti H, El Mostaphi A, Barrahi M, Ben Ali A, Chahboun N. Chemical composition and antibacterial activity of the essential oil of Myrtus communis leaves. Karbala International Journal of Modern Science 6 (2020) 249-258.

7. Sadeghi Nejad B, Erfani Nejad M, Yusef Naanaie S, Zarrin M. Antifungal efficacy of Myrtus communis Linn. Jentashapir Journal of Health Research 5 (2014) e21879.

8. Tuberoso CIG., Rosa, A., Bifulco E, Melis MP, Atzeri A, Pirisi FM, \& Dessì MA. Chemical composition and antioxidant activities of Myrtus communis L. berries extracts. Food Chemistry 123 (2010) 1242-1251.

9. Gul C, Nazligul Y. A Current Approach to Helminthiasis. Dirim Medical Journal 83 (2008) 40-48.

10. Bethony J, Brooker S, Albonico M, Geiger, SM, Loukas A, Diemert D, \& Hotez PJ. Soil-transmitted helminth infections: ascariasis, 
trichuriasis, and hookworm. The Lancet 367 (2006) 1521-1532.

11. Drake L, Bundy D. Multiple helminth infections in children: impact and control. Parasitology 122 (2001) 73-81.

12. Gatti S, Lopes R, Cevini C, Ijaoba, B, Bruno A, Bernuzzi AM, Scaglia M. Intestinal parasitic infections in an institution for the mentally retarded. Annals of Tropical Medicine \& Parasitology 94 (2000) 453-460.

13. Tappeh KH, Mohammadzadeh H, Rahim RN, Barazesh A, Khashaveh S, Taherkhani H. Prevalence of intestinal parasitic infections among mentally disabled children and adults of Urmia, Iran. Iranian Journal of Parasitology 5 (2010) 60-64.

14. Kaminsky R, Ducray P, Jung M, Clover R, Rufener L, Bouvier J \& Mäser P. A new class of anthelmintics effective against drugresistant nematodes. Nature 452 (2008) 176-181.

15. Smout MJ, Kotze AC, McCarthy JS, Loukas A. A novel high throughput assay for anthelmintic drug screening and resistance diagnosis by real-time monitoring of parasite motility. Plos Neglected Tropical Diseases 4 (2010) e885.

16. Ozpınar N. A model Organism for Antihelminthic Activity: Caenorhabditis elegans and Nigella sativa. Turkish Journal of Parasitology 44 (2020) 31.

17. Hernando G, Turani O, Bouzat C. Caenorhabditis elegans muscle Cys-loop receptors as novel targets of terpenoids with potential anthelmintic activity. Plos Neglected Tropical Diseases 13 (2019) e0007895.

18. Kaewintajuk K, Cho PY, Kim SY, Lee ES, Lee HK, Choi EB, \& Park, H. Anthelmintic activity of KSI-4088 against Caenorhabditis elegans. Parasitology Research 107 (2010) 27-30.

19. Shaapan RM, Al-Abodi HR, Alanazi AD, Abdel-Shafy S, Rashidipour M, Shater AF, \& Mahmoudvand H. Myrtus communis Essential Oil; Anti-Parasitic Effects and Induction of the Innate Immune System in Mice with Toxoplasma gondii Infection. Molecules 26 (2021) 819.

20. Mahmoudvand H, Ezzatkhah F, Sharififar F, Sharifi I, Dezaki ES. Antileishmanial and cytotoxic effects of essential oil and methanolic extract of Myrtus communis L. The Korean Journal of Parasitology 53 (2015) 21-27.

21. Abdalla SF, Ramadan NI, Mohamed AA, El-Deeb HK, Al-Khadrawy FM, Badawy AF. A study on the effect of Myrtus communis and Olibanum on Giardia lamblia infection in Egypt. Parasitologists United Journal 4 (2011) 89-100.

22. Azadbakht M, Ziaiye H, Abdollahi F, Shabankhani B. Effect of Methanolic essence and extract of Myrtus communis on Trichomonas vaginalis. Journal of Guilan University of Medical Sciences 12 (2004) 8-13.

23. Abdollahy F, Ziaei H, Shabankhani B, Azadbakht M. Effect of essential oils of Artemisia aucheri Boiss. Zataria multiflora Boiss, and Myrtus communis L. on Trichomonas vaginalis. Iranian Journal of Pharmaceutical Research (2010) 35

24. Moussouni L, Besseboua O, Abdelhanine A. Anthelmintic activity of aqueous and ethanol extracts of Urtica dioica L. and Myrtus communis L. leaves on bovine digestive strongyles: in-vitro study. Ataturk University Journal of Veterinary Sciences 14 (2019) 273-283.

25. Vickers NJ. Animal communication: when I'm calling you, will you answer too? Current Biology 27 (2017) 713-715.
26. Oliveira GL, Vieira TM, Nunes VF, Ruas MDO, Duarte ER, Moreira DDL, \& Martins ER. Chemical composition and efficacy in the egg-hatching inhibition of essential oil of Piper aduncum against Haemonchus contortus from sheep. Revista Brasileira de Farmacognosia 24 (2014) 288-292.

27. Pinto, N. B., Castro, L. M. D., Azambuja, R. H. M., Capella, G. D. A., Moura, M. Q. D., Terto, W. D., ... \& Leite, F. P. L. Ovicidal and larvicidal potential of Rosmarinus officinalis to control gastrointestinal nematodes of sheep. Revista Brasileira de Parasitologia Veterinária 28 (2019) 807-811.

28. Pessoa L, Morais S, Bevilaqua C, Luciano J. Anthelmintic activity of essential oil of Ocimum gratissimum Linn. and eugenol against Haemonchus contortus. Veterinary Parasitology 109 (2002) 59-63.

29. Malheiros DF, Sarquis IR, Ferreira IM, Mathews PD, Mertins O, Tavares-Dias M. Nanoemulsions with oleoresin of Copaifera reticulata (Leguminosae) improve anthelmintic efficacy in the control of monogenean parasites when compared to oleoresin without nanoformulation. Journal of Fish Diseases 43 (2020) 687695.

30. Lalthanpuii PB, Lalchhandama K. Phytochemical analysis and in vitro anthelmintic activity of Imperata cylindrica underground parts. BMC Complementary Medicine and Therapies 20 (2020) 1-9.

31. Lalthanpuii P, Zokimi Z, Lalchhandama K. The toothache plant (Acmella oleracea) exhibits anthelmintic activity on both parasitic tapeworms and roundworms. Pharmacognosy Magazine 16 (2020) 193-198.

32. Hernandez PM, Salem AZ, Elghandour MM, Cipriano-Salazar M, Cruz-Lagunas B, Camacho LM. Anthelmintic effects of Salix babylonica L. and Leucaena leucocephala Lam. extracts in growing lambs. Tropical Animal Health and Production 46 (2014) 173-178.

33. Panda SK, Das R, Mai AH, De Borggraeve WM, Luyten W. Nematicidal Activity of Holigarna caustica (Dennst.) Oken Fruit Is Due to Linoleic Acid. Biomolecules 10 (2020) 1043-1054.

34. Štrbac F, Bosco A, Amadesi A, Rinaldi L, Stojanović D, Simin N, Orčić D, Pušić I, Krnjajić S, Ratajac R. In vitro ovicidal activity of two chemotypes of the yarrow (Achillea millefolium L.) essential oil against sheep gastrointestinal nematodes. Archives of Veterinary Medicine 13 (2020) 59-76.

35. Taur D, Kulkarni V, Patil R. Chromatographic evaluation and anthelmintic activity of Eucalyptus globulus oil. Pharmacognosy Research 2 (2010) 125-127.

36. Kaplan RM, Storey BE, Vidyashankar AN, Bissinger BW, Mitchell SM, Howell SB, Mason ME, Lee MD, Pedroso AA, Akashe A, Skrypec DJ. Antiparasitic efficacy of a novel plant-based functional food using an Ascaris suum model in pigs. Acta Tropica 139 (2014) $15-22$.

37. Matos-Rocha TJ, dos Santos Cavalcanti MG, Barbosa-Filho JM, et al. In vitro evaluation of schistosomicidal activity of essential oil of Mentha $\mathrm{x}$ villosa and some of its chemical constituents in adult worms of Schistosoma mansoni. Planta Medica. 79 (2013) 13071312 . 